\title{
An Efficient Synthesis of Phenols via Oxidative Hydroxylation of Arylboronic Acids Using $\left(\mathrm{NH}_{4}\right)_{2} \mathrm{~S}_{2} \mathrm{O}_{8}$
}

\author{
Claudia A. Contreras-Celedón, Luis Chacón-García, and Nancy Judith Lira-Corral
}

Laboratorio de Diseño Molecular, Instituto de Investigaciones Químico Biológicas, Universidad Michoacana de San Nicolás de Hidalgo, Edificio B-1, Ciudad Universitaria, 58030 Morelia, MICH, Mexico

Correspondence should be addressed to Claudia A. Contreras-Celedón; celedon@umich.mx

Received 19 December 2013; Accepted 8 February 2014; Published 17 March 2014

Academic Editor: Dario Pasini

Copyright (C) 2014 Claudia A. Contreras-Celedón et al. This is an open access article distributed under the Creative Commons Attribution License, which permits unrestricted use, distribution, and reproduction in any medium, provided the original work is properly cited.

A mild and efficient method for the ipso-hydroxylation of arylboronic acids to the corresponding phenols was developed using $\left(\mathrm{NH}_{4}\right)_{2} \mathrm{~S}_{2} \mathrm{O}_{8}$ as an oxidizing agent. The reactions were performed under metal-, ligand-, and base-free conditions.

\section{Introduction}

Phenol and its derivatives are present in numerous natural products (e.g., aromatic steroids, cannabinoids, macrolides, quinines, terpenoids, lignans, and alkaloids) and serve as key synthetic intermediates for the construction of complex structures [1-5]. In medicinal chemistry, they are known to exhibit many pharmacological actions including antitumor, antiviral, antibacterial, cardioprotective, and antimutagenic activities [6-10]. The development of methods for accessing such structural motifs, therefore, remains an area of intensive research. In laboratory-scale synthesis, phenols are routinely prepared through the nucleophilic substitution of an activating aryl halide [11] in a copper-catalyzed transformation of a diazoarene [12] or through the Pd-catalyzed conversion of an aryl halide to a phenol using phosphine ligands [13]. These methods, however, often suffer from several drawbacks, such as poor functional group compatibility, narrow substrate scope, harsh reaction conditions, and difficulties in obtaining the starting materials, which limit their utility and applicability. Phenols have been identified as by-products in many metal-catalyzed reactions of arylboronic acids [14]; however, only a few reports have described methodologies for the hydroxylation of arylboronic acids. Although the oxidation of arylboronic acid is not a popular or economical approach for preparing phenols, it provides access to phenols that may be difficult to obtain by other means [15].
In recent years, arylboronic acid derivatives have emerged as one of the most efficient and powerful synthetic precursors for facile regioselective functional group transformations [16]. They are innocuous (generally nontoxic and stable to heat, air, and moisture) and available in a wide range of structures and often react under mild conditions with good functional group tolerance, making them an interesting and valuable potential precursor for phenols. The oxidation of arylboronic acids and their derivatives to phenols with alkaline hydrogen peroxide was first reported by Ainley and Challenger [17] and was later modified by Kuivila [18] and Simon et al. [19]. Although this transformation is simple and green, when electron-deficient arylboronic acids and sensitive substituents are present, give low yields and alkaline hydrogen peroxide can lead to undesirable side reactions.

In this context, some reports have described the preparation of phenols from arylboronic acid using oxone [20, 21], $\mathrm{Cu}(\mathrm{OAc})_{2}-\mathrm{H}_{2} \mathrm{O}_{2}$ [19], $\mathrm{NH}_{2} \mathrm{OH}$ [22], $\mathrm{H}_{2} \mathrm{O}_{2}$ - $\operatorname{poly}(N-$ vinylpyrrolidone) [23], $\mathrm{CuSO}_{4}$ - phenanthroline [24], $\mathrm{CuCl}_{2}-$ micellar systems [25], $\mathrm{I}_{2}-\mathrm{H}_{2} \mathrm{O}_{2}$ [26], photoredox catalysis [27], electrochemical reactions [28], N-oxides [29], Amberlite IR-120- $\mathrm{H}_{2} \mathrm{O}_{2}$ [30], $\mathrm{Al}_{2} \mathrm{O}_{3}-\mathrm{H}_{2} \mathrm{O}_{2}$ [31], MCPBA [32], and $\mathrm{NaClO}_{2}$ [33]. Although these methods often provide good yields, in the majority of cases, these strategies have some disadvantages such as harsh reaction conditions, long time reactions, the use of transition metals with ligands or base, chlorinated organic solvents as reaction media, or expensive 
reagents. Thus the developments of protocols that are readily accessible, air and moisture stable, inexpensive, and environmentally acceptable and that can promote these reactions under mild reaction are still desirable.

The present study sought to develop an efficient conversion of substituted arylboronic acids to substituted phenols by an oxidative hydroxylation reaction using $\left(\mathrm{NH}_{4}\right)_{2} \mathrm{~S}_{2} \mathrm{O}_{8}$ under metal-, ligand-, and base-free conditions. Ammonium peroxodisulfate is an inexpensive easily available reagent, a "green" oxidizer that is widely used in industry for bleaching and waste water treatment. However, only scanty literature is available that describes its applications in organic synthesis. The compound has been used to accomplish certain oxidations of alkenes [34], benzyl alcohols [35], and substituted aromatics [36].

\section{Materials and Methods}

Arylboronic acids were obtained from Aldrich Chemical Co. Reagents and solvents were of the highest quality available and used as received. Flash chromatography purification was performed on silica gel 60 (230-400 mesh). All products are known compounds and were characterized by comparing the physical and NMR data to published information. NMR spectra were recorded at 200 and $400 \mathrm{MHz}$, chemical shift in ppm relative to TMS as an internal standard. Microwave heated reactions were performed in a CEM Discover reactor.

2.1. General Procedure for the Hydroxylation of Arylboronic Acid. To a solution of $50 \mathrm{mg}$ arylboronic acid $(0.41 \mathrm{mmol}$, 1.0 equiv.) in $3 \mathrm{~cm}^{3} \mathrm{MeOH}: \mathrm{H}_{2} \mathrm{O}(6: 1)$ was added 2.5 equiv. $\mathrm{NH}_{4} \mathrm{~S}_{2} \mathrm{O}_{8}$, and the mixture was stirred at $80^{\circ} \mathrm{C}$ for the time indicated in Scheme 1. The reaction progress was monitored by TLC, and the reaction was determined to have reached completion when the starting material had been completely consumed. The solvent was evaporated under reduced pressure and extracted with AcOEt. The organic phase was separated and dried over anhydrous $\mathrm{Na}_{2} \mathrm{SO}_{4}$. The solvent was removed under vacuum, and the compound was purified by column chromatography using hexane: AcOEt $(9: 1)$ as an eluent. All compounds were characterized by ${ }^{1} \mathrm{H}$ NMR, ${ }^{13} \mathrm{C}$ $\mathrm{NMR}$, and MS and by comparison with the properties of known samples.

2.2. General Procedure for the Hydroxylation of Arylboronic Acid under Microwave Irradiation. To a solution of $50 \mathrm{mg}$ arylboronic acid $(0.41 \mathrm{mmol}, 1.0$ equiv. $)$ in $3 \mathrm{~cm}^{3}$ $\mathrm{MeOH}: \mathrm{H}_{2} \mathrm{O}(6: 1)$ was added 2.5 equiv. $\mathrm{NH}_{4} \mathrm{~S}_{2} \mathrm{O}_{8}$, and the mixture was stirred at $105^{\circ} \mathrm{C}$ and $300 \mathrm{~W}$ for $15 \mathrm{~min}$. The solvent was evaporated under reduced pressure and extracted with AcOEt. The organic phase was separated and dried over anhydrous $\mathrm{Na}_{2} \mathrm{SO}_{4}$. The solvent was removed under vacuum, and the compound was purified by column chromatography using hexane:AcOEt $(9: 1)$ as an eluent. All compounds were characterized by ${ }^{1} \mathrm{H}$ NMR, ${ }^{13} \mathrm{C}$ NMR, and MS and by comparison to the properties of known samples.

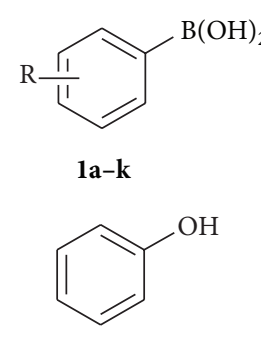

2a, $98 \%, 3 \mathrm{~h}$<smiles>COc1ccccc1O</smiles>

2d, $91 \%, 2 \mathrm{~h}$<smiles>Oc1ccc(Br)cc1</smiles>

$2 g, 98 \%, 3 \mathrm{~h}$

2j, $98 \%, 5$ h<smiles>N#Cc1ccc(O)cc1</smiles>

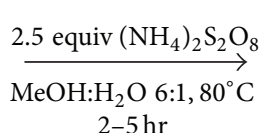<smiles>[R][X]c1ccc(O)cc1</smiles><smiles>Oc1ccc(O)cc1</smiles>

2b, $92 \%, 4 h$<smiles>Cc1ccc(O)cc1</smiles>

2e, $93 \%, 3 \mathrm{~h}$<smiles>O=Cc1ccc(O)cc1</smiles>

2h, $91 \%, 3 \mathrm{~h}$<smiles>O=[N+]([O-])c1cccc(O)c1</smiles>

2k, $90 \%, 3$ h
$2 a-k$<smiles>COc1ccc(O)cc1</smiles>

2c, $89 \%, 5 \mathrm{~h}$<smiles>Oc1ccc(F)cc1</smiles>

2f, $98 \%, 3 \mathrm{~h}$<smiles>Oc1ccc(C(F)(F)F)cc1</smiles>

$2 i, 93 \%, 5$ h
SCHEme 1: The hydroxylation reactions of $\mathbf{1 a}-\mathbf{1 k}$. Yield of the isolated product. All compounds were characterized by ${ }^{1} \mathrm{H}$ NMR and ${ }^{13} \mathrm{C}$ NMR.

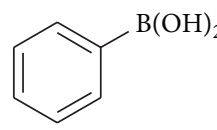

1a

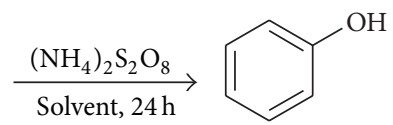

$2 \mathbf{a}$
Figure 1

\section{Results and Discussion}

Our study began by optimizing the reaction conditions. The effectiveness of $\left(\mathrm{NH}_{4}\right)_{2} \mathrm{~S}_{2} \mathrm{O}_{8}$ toward oxidative hydroxylation was explored using phenylboronic acid la as a model substrate, Figure 1. Mixtures of $\mathbf{1 a}$ and $\left(\mathrm{NH}_{4}\right)_{2} \mathrm{~S}_{2} \mathrm{O}_{8}$ (1.0 equiv.) were prepared in several solvents by stirring at $0^{\circ} \mathrm{C}$ for $24 \mathrm{~h}$. The phenol 2a was not obtained at all. In the same reaction at room temperature, only low yields of $2 \mathbf{a}$ were observed. Increasing the reaction temperature to $50^{\circ} \mathrm{C}$ or $80^{\circ} \mathrm{C}$ provided a range of yields, although the reaction did not reach completion. As shown in Table 1, the reaction proceeded in both protic and aprotic solvents, and the yield tended to vary with the solvent.

Several test reactions were carried out using different amounts of $\left(\mathrm{NH}_{4}\right)_{2} \mathrm{~S}_{2} \mathrm{O}_{8}$ to establish the optimal amount of catalyst required for this transformation. $\mathrm{MeOH}: \mathrm{H}_{2} \mathrm{O}$ in a $6: 1$ ratio was employed as the solvent. It was found that 2.5 equiv. (Table 2 , entry 4 ) was necessary to achieve the 
TABLE 1: Effects of the solvent and temperature on the hydroxylation of $1 a^{a}$.

\begin{tabular}{lccc}
\hline Entry & Solvent & Temperature $\left({ }^{\circ} \mathrm{C}\right)$ & 2a yield ${ }^{\mathrm{b}}(\%)$ \\
\hline \multirow{2}{*}{1} & Toluene $: \mathrm{H}_{2} \mathrm{O} 6: 1$ & 50 & 23 \\
& & 80 & 53 \\
\hline \multirow{2}{*}{2} & \multirow{2}{*}{ Dioxane $: \mathrm{H}_{2} \mathrm{O} 6: 1$} & 50 & 28 \\
& & 80 & 47 \\
\hline \multirow{2}{*}{3} & \multirow{2}{*}{ Acetone $: \mathrm{H}_{2} \mathrm{O} 6: 1$} & 50 & 33 \\
& & 80 & 52 \\
\hline \multirow{2}{*}{4} & \multirow{2}{*}{ AcCN $: \mathrm{H}_{2} \mathrm{O} 6: 1$} & 50 & 30 \\
& & 80 & 45 \\
\hline \multirow{2}{*}{5} & \multirow{2}{*}{$\mathrm{MeOH}: \mathrm{H}_{2} \mathrm{O} 6: 1$} & 50 & 32 \\
& & 80 & 65 \\
\hline \multirow{2}{*}{6} & \multirow{2}{*}{$\mathrm{H}_{2} \mathrm{O}$} & 50 & 4 \\
& & 80 & 13 \\
\hline
\end{tabular}

a Reactions conditions: 1a $(0.41 \mathrm{mmol}),\left(\mathrm{NH}_{4}\right)_{2} \mathrm{~S}_{2} \mathrm{O}_{8}$ (1.0 equiv.), solvent $3 \mathrm{~mL}$, and $24 \mathrm{~h}$. ${ }^{\mathrm{b}}$ Yield determined by ${ }^{\mathrm{l}} \mathrm{H}$ NMR.

TABLE 2: Effects of $\left(\mathrm{NH}_{4}\right)_{2} \mathrm{~S}_{2} \mathrm{O}_{8}$ on the hydroxylation of $\mathbf{1} \mathbf{a}^{\mathrm{a}}$.

\begin{tabular}{|c|c|c|c|}
\hline Entry & $\left(\mathrm{NH}_{4}\right)_{2} \mathrm{~S}_{2} \mathrm{O}_{8}$ (equiv.) & Time (h) & 2a yield ${ }^{\mathrm{b}, \mathrm{c}}(\%)$ \\
\hline \multirow{3}{*}{1} & \multirow{3}{*}{0.0} & 3 & $\mathrm{Nr}$ \\
\hline & & 10 & $\mathrm{Nr}$ \\
\hline & & 24 & $\mathrm{Nr}$ \\
\hline \multirow{3}{*}{2} & \multirow{3}{*}{1.0} & 3 & $39^{\mathrm{b}, \mathrm{c}}$ \\
\hline & & 10 & $52^{\mathrm{b}, \mathrm{c}}$ \\
\hline & & 24 & $65^{\mathrm{b}, \mathrm{c}}$ \\
\hline \multirow{3}{*}{3} & \multirow{3}{*}{2.0} & 3 & $64^{\mathrm{b}, \mathrm{c}}$ \\
\hline & & 10 & $79^{\mathrm{b}, \mathrm{c}}$ \\
\hline & & 24 & $85^{\mathrm{b}, \mathrm{c}}$ \\
\hline 4 & 2.5 & 3 & $98^{\mathrm{d}}$ \\
\hline
\end{tabular}

smooth oxidation of 1.0 equiv. of the substrate 1a. Essentially no product $\mathbf{2 a}$ was obtained from the reaction in the absence of $\left(\mathrm{NH}_{4}\right)_{2} \mathrm{~S}_{2} \mathrm{O}_{8}$ (Table 2, entry 1).

The scope and limitations of the current procedure were evaluated by treating a wide array of electronically diverse arylboronic acids with 2.5 equiv. $\left(\mathrm{NH}_{4}\right)_{2} \mathrm{~S}_{2} \mathrm{O}_{8}$ in $\mathrm{MeOH}: \mathrm{H}_{2} \mathrm{O}$ $(6: 1)$ at $80^{\circ} \mathrm{C}$. By using different arylboronic acid $\mathbf{1 b}-\mathbf{1 k}$, the method proved to be compatible with a wide range of substrates and $\mathbf{1 b} \mathbf{b}-\mathbf{1 k}$ were converted into the corresponding products $\mathbf{2 b} \mathbf{b}-\mathbf{2 k}$ in good to excellent yields. In contrast with the traditional nucleophilic substitution of aryl halides, the method preferred to offer the electron-rich phenols easily.

Over the past 25 years, microwave chemistry techniques have been recognized as a powerful method for performing challenging reactions in short amounts of time with a high yield and high purity. We therefore focused on reducing the reaction time using microwave irradiation. Here also, we chose $\mathrm{MeOH}: \mathrm{H}_{2} \mathrm{O}$ as our reaction medium because of its polarity, which is suitable for microwave heating.<smiles>Oc1ccccc1</smiles>

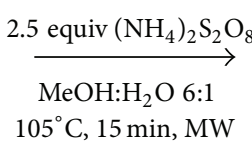<smiles>[R]c1ccc(O)cc1</smiles>

2a-k<smiles>Oc1ccc(O)cc1</smiles>

2b, $96 \%$<smiles>COc1ccc(O)cc1</smiles>

2a, $94 \%$<smiles>COc1ccccc1O</smiles><smiles>Cc1ccc(O)cc1</smiles><smiles>Oc1ccc(F)cc1</smiles>

2d, $88 \%$<smiles>Oc1ccc(Br)cc1</smiles>

2g, $92 \%$<smiles>O=Cc1ccc(O)cc1</smiles><smiles>Oc1ccc(C(F)(F)F)cc1</smiles>

2i, $89 \%$<smiles>N#Cc1ccc(O)cc1</smiles>

$2 \mathbf{j}, 96 \%$ 2h, $90 \%$<smiles>O=[N+]([O-])c1cccc(O)c1</smiles>

$2 \mathbf{k}, 92 \%$

SCHEME 2: Hydroxylation reaction of $\mathbf{1 a}-\mathbf{1 k}$ under microwave irradiation. Reaction conditions: $\mathbf{1 a}(0.41 \mathrm{mmol}, 1$ equiv. $), \mathrm{MeOH}: \mathrm{H}_{2} \mathrm{O}$ $6: 1(3 \mathrm{~mL}),\left(\mathrm{NH}_{4}\right)_{2} \mathrm{~S}_{2} \mathrm{O}_{8}$ (2.5 equiv.), $105^{\circ} \mathrm{C}, 300 \mathrm{~W}$, and $15 \mathrm{~min}$. Yield of the isolated product. All compounds were characterized by ${ }^{1} \mathrm{H}$ NMR and ${ }^{13} \mathrm{C}$ NMR.

Using the established conditions, we irradiated the diverse arylboronic acid substrates (1 equiv.) in the presence of ammonium peroxodisulfate (2.5 equiv.) in $\mathrm{MeOH}: \mathrm{H}_{2} \mathrm{O}(6: 1$, $3 \mathrm{~mL}$ ) at $105^{\circ} \mathrm{C}, 300 \mathrm{~W}$ for $15 \mathrm{~min}$. The Discover LabMate model reactor from CEM Corporation connected to an IR thermometer for temperature monitoring and control was used. The MW parameters were set at $105^{\circ} \mathrm{C}$ and $300 \mathrm{~W}$ power with a $15 \mathrm{~min}$ reaction time, excluding the time taken to reach the temperature ("ramp time"). The "ramp time" was approximately $1 \mathrm{~min}$ without the use of the "cooling mode" option. Then the power was zeroed and the irradiation was automatically applied periodically to keep the temperature stable at $105^{\circ} \mathrm{C}$ for the time of the reaction. Stirring was applied during MW irradiation. The results are summarized in Scheme 2.

\section{Conclusions}

We developed a mild, efficient, and comparatively cheap method for synthesizing phenols via oxidative hydroxylation of arylboronic acids using $\left(\mathrm{NH}_{4}\right)_{2} \mathrm{~S}_{2} \mathrm{O}_{8}$. The reaction was applied to arylboronic acids with either electron-withdrawing or electron-donating substituents. The substrates underwent an ipso-hydroxylation reaction in good yields (88-98\%). The 
reactions were performed under metal-, ligand-, and basefree conditions. This transformation is broadly compatible with a variety of functional groups.

\section{Conflict of Interests}

The authors declare that there is no conflict of interests regarding the publication of this paper.

\section{Acknowledgment}

The authors thank the CIC-UMSNH for support of this work.

\section{References}

[1] E. Poupon and B. Nay, Biomimetic Organic Synthesis, WileyVCH, Weinheim, Germany, 2011.

[2] Z. Rappoport, The Chemistry of Phenols, Wiley-VCH, Weinheim, Germany, 2003.

[3] J. H. P. Tyman, Synthetic and Natural Phenols, Elsevier, New York, NY, USA, 1996.

[4] M. Caricato, N. J. Leza, K. Roy et al., "A chiroptical probe for sensing metal ions in water," European Journal of Organic Chemistry, vol. 2013, no. 27, pp. 6078-6083, 2013.

[5] Y. Baudry, G. Bollot, V. Gorteau et al., "Molecular recognition by synthetic multifunctional pores in practice: are structural studies really helpful?" Advanced Functional Materials, vol. 16, no. 2, pp. 169-179, 2006.

[6] R. W. Owen, A. Giacosa, W. E. Hull, R. Haubner, B. Spiegelhalder, and H. Bartsch, "The antioxidant/anticancer potential of phenolic compounds isolated from olive oil," European Journal of Cancer, vol. 36, no. 10, pp. 1235-1247, 2000.

[7] K. Likhitwitayawuid, B. Sritularak, K. Benchanak, V. Lipipun, J. Mathew, and R. F. Schinazi, "Phenolics with antiviral activity from Millettia erythrocalyx and Artocarpus lakoocha," Natural Product Research, vol. 19, no. 2, pp. 177-182, 2005.

[8] R. Puupponen-Pimiä, L. Nohynek, C. Meier et al., "Antimicrobial properties of phenolic compounds from berries," Journal of Applied Microbiology, vol. 90, no. 4, pp. 494-507, 2001.

[9] J. M. Wu, Z. R. Wang, T. C. Hsieh, J. L. Bruder, J. G. Zou, and Y. Z. Huang, "Mechanism of cardioprotection by resveratrol, a phenolic antioxidant present in red wine (review)," International Journal of Molecular Medicine, vol. 8, no. 1, pp. 3-17, 2001.

[10] E. González de Mejía, E. Castaño-Tostado, and G. LoarcaPiña, "Antimutagenic effects of natural phenolic compounds in beans," Mutation Research, vol. 441, no. 1, pp. 1-9, 1999.

[11] A. Mehmood and N. E. Leadbeater, "Copper-catalyzed direct preparation of phenols from aryl halides," Catalysis Communications, vol. 12, no. 1, pp. 64-66, 2010.

[12] C. Hoarau and T. R. R. Pettus, "Strategies for the preparation of differentially protected ortho-prenylated phenols," Synlett, no. 1, pp. 127-137, 2003.

[13] T. Schulz, C. Torborg, B. Schäffner et al., "Practical imidazolebased phosphine ligands for selective palladium-catalyzed hydroxylation of aryl halides," Angewandte Chemie, vol. 48, no. 5, pp. 918-921, 2009.

[14] H. Sakurai, H. Tsunoyama, and T. Tsukuda, "Oxidative homocoupling of potassium aryltrifluoroborates catalyzed by gold nanocluster under aerobic conditions," Journal of Organometallic Chemistry, vol. 692, no. 1-3, pp. 368-374, 2007.
[15] R. Chen, H. Liu, X. Liu, and X. Chen, "An efficient synthesis of L-3,4,5-trioxygenated phenylalanine compounds from Ltyrosine," Tetrahedron, vol. 69, no. 17, pp. 3565-3570, 2013.

[16] D. G. Hall, Boronic Acids: Preparation and Applications in Organic Synthesis, Medicine and Materials, vol. 1 and 2, WileyVCH, 2011.

[17] A. D. Ainley and F. Challenger, "CCLXXX. Studies of the boroncarbon linkage. Part I: the oxidation and nitration of phenylboric acid," Journal of the Chemical Society, pp. 2171-2180, 1930.

[18] H. G. Kuivila, "Electrophilic displacement reactions. III: kinetics of the reaction between hydrogen peroxide and benzeneboronic acid," Journal of the American Chemical Society, vol. 76, no. 3, pp. 870-874, 1954.

[19] J. Simon, S. Salzbrunn, G. K. Surya Prakash, N. A. Petasis, and G. A. Olah, "Regioselective conversion of arylboronic acids to phenols and subsequent coupling to symmetrical diaryl ethers," Journal of Organic Chemistry, vol. 66, no. 2, pp. 633-634, 2001.

[20] K. S. Webb and D. Levy, "A facile oxidation of boronic acids and boronic esters,” Tetrahedron Letters, vol. 36, no. 29, pp. 5117-5118, 1995.

[21] R. E. Maleczka Jr., F. Shi, D. Holmes, and M. R. Smith III, "Regioselective conversion of arylboronic acids to phenols and subsequent coupling to symmetrical diaryl ethers," Journal of the American Chemical Society, vol. 125, no. 26, pp. 7792-7793, 2003.

[22] E. Kianmehr, M. Yahyaee, and K. Tabatabai, "A mild conversion of arylboronic acids and their pinacolyl boronate esters into phenols using hydroxylamine," Tetrahedron Letters, vol. 48, no. 15, pp. 2713-2715, 2007.

[23] G. K. S. Prakash, S. Chacko, C. Panja et al., "Regioselective synthesis of phenols and halophenols from arylboronie acids using solid poly ( $N$-vinylpyrrolidone)/hydrogen peroxide and poly $(4-$ vinylpyridine) /hydrogen peroxide complexes," Advanced Synthesis and Catalysis, vol. 351, no. 10, pp. 1567-1574, 2009.

[24] J. Xu, X. Wang, C. Shao, D. Su, G. Cheng, and Y. Hu, "Highly efficient synthesis of phenols by copper-catalyzed oxidative hydroxylation of arylboronic acids at room temperature in water," Organic Letters, vol. 12, no. 9, pp. 1964-1967, 2010.

[25] K. Inamoto, K. Nozawa, M. Yonemoto, and Y. Kondo, "Micellar system in copper-catalysed hydroxylation of arylboronic acids: facile access to phenols," Chemical Communications, vol. 47, no. 42, pp. 11775-11777, 2011.

[26] A. Gogoi and U. Bora, "An iodine-promoted, mild and efficient method for the synthesis of phenols from arylboronic acids," Synlett, vol. 23, no. 7, pp. 1079-1081, 2012.

[27] Y. Q. Zou, J. R. Chen, X. P. Liu et al., "Highly efficient aerobic oxidative hydroxylation of arylboronic acids: photoredox catalysis using visible light," Angewandte Chemie, vol. 51, no. 3, pp. 784-788, 2012.

[28] H. Jiang, L. Lykke, S. U. Pedersen, W. J. Xiao, and K. A. Jørgensen, "A practical electromediated ipso-hydroxylation of aryl and alkyl boronic acids under an air atmosphere," Chemical Communications, vol. 48, pp. 7203-7205, 2012.

[29] C. Zhu, R. Wang, and J. R. Falck, "Mild and rapid hydroxylation of aryl/heteroaryl boronic acids and boronate esters with $\mathrm{N}$ oxides," Organic Letters, vol. 14, pp. 3494-3497, 2012.

[30] N. Mulakayala, Ismail, K. M. Kumar et al., "Catalysis by Amberlite IR-120 resin: a rapid and green method for the synthesis of phenols from arylboronic acids under metal, ligand, and base-free conditions," Tetrahedron Letters, vol. 53, no. 45, pp. 6004-6007, 2012. 
[31] A. Gogoi and U. Bora, "A mild and efficient protocol for the ipsohydroxylation of arylboronic acids," Tetrahedron Letters, vol. 54, pp. 1821-1823, 2013.

[32] D. S. Chen and J. M. Huang, "A mild and highly efficient conversion of arylboronic acids into phenols by oxidation with MCPBA," Synlett, vol. 24, no. 4, pp. 499-501, 2013.

[33] P. Gogoi, P. Bezboruah, J. Gogoi, and R. C. Boruah, “ipsoHydroxylation of arylboronic acids and boronate esters by using sodium chlorite as an oxidant in water," European Journal of Organic Chemistry, vol. 2013, no. 32, pp. 7291-7294, 2013.

[34] W. E. Fristad and J. R. Peterson, "Iron(II) catalyzed persulfate oxidation of alkenes to vicinal diacetates," Tetrahedron Letters, vol. 24, no. 42, pp. 4547-4550, 1983.

[35] G. Gelbard, "Polymer-supported reagents", in Handbook of Green Chemistry and Technology, J. H. Clark and D. Macquarrie, Eds., Blackwell Science, Oxford, UK, 2002.

[36] A. Clerici and O. Porta, "Oxidation of substituted aromatic compounds by peroxydisulphate. Homolytic benzylation and oxidative coupling reaction," Journal of Chemistry, vol. 58, no. 19, pp. 2117-2119, 1980. 

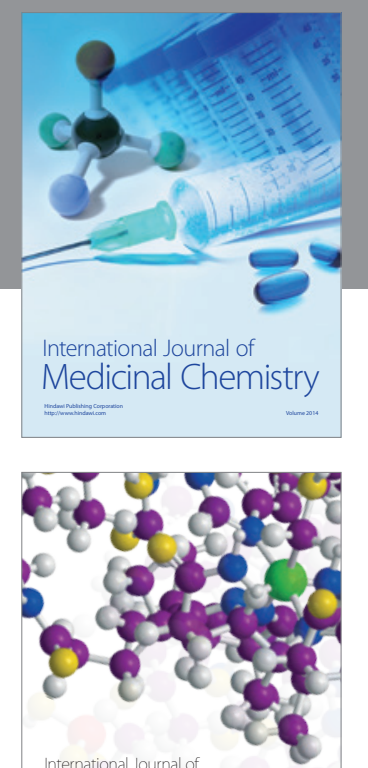

\section{Carbohydrate} Chemistry

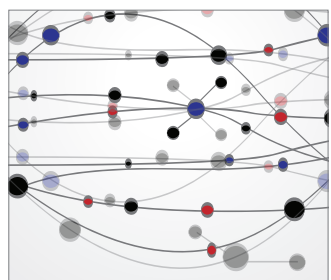

The Scientific World Journal
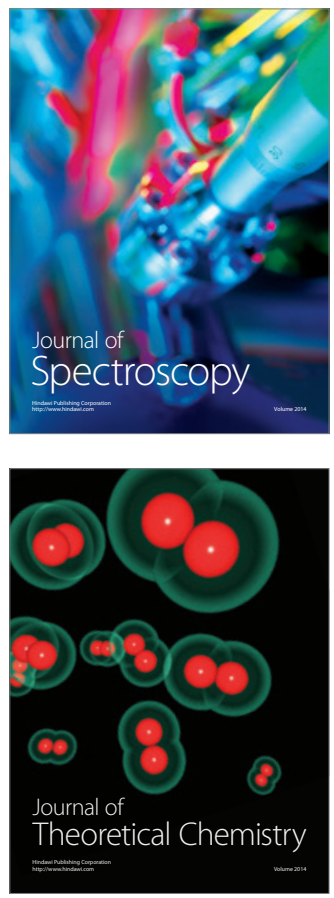
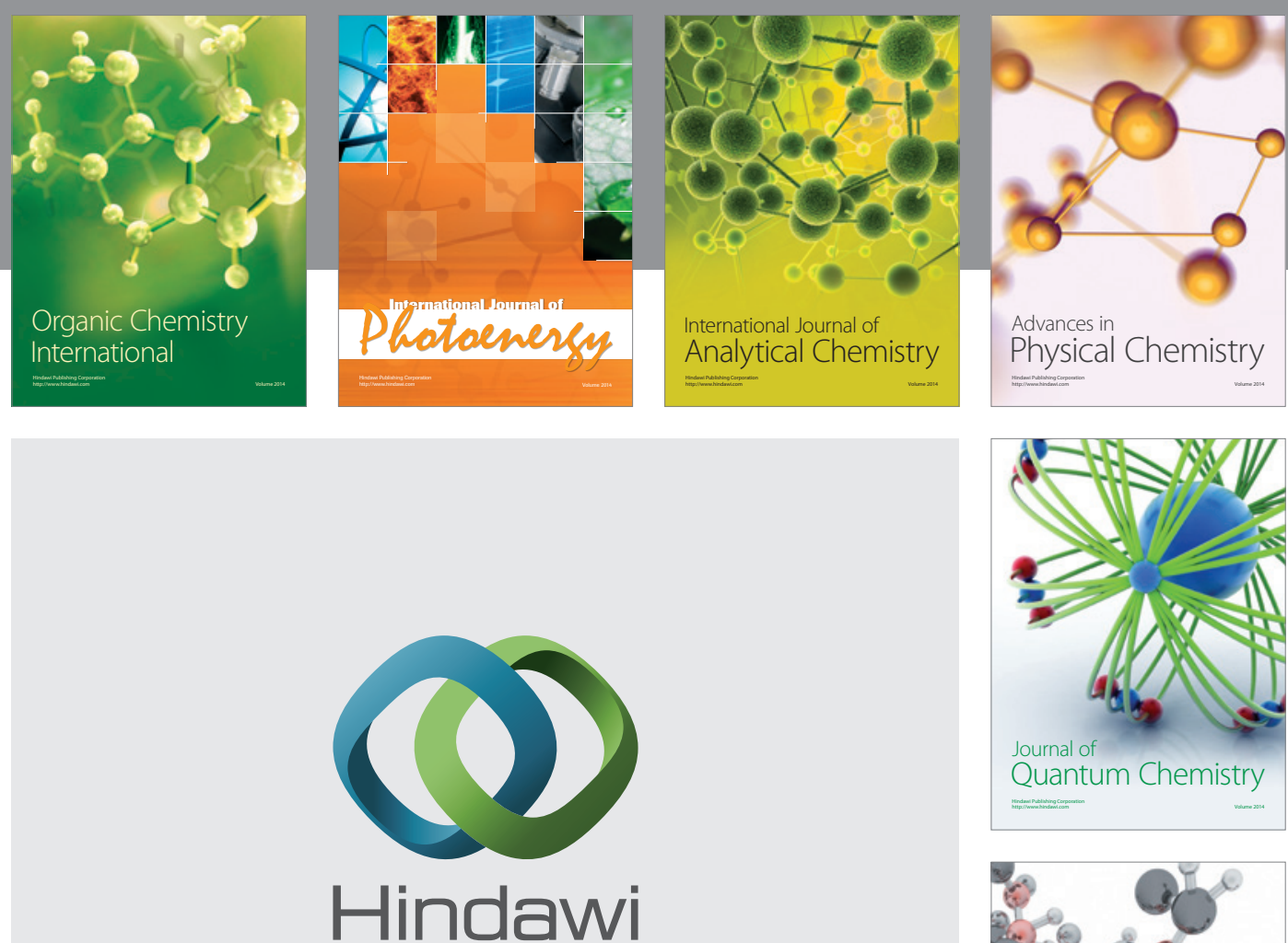

Submit your manuscripts at

http://www.hindawi.com

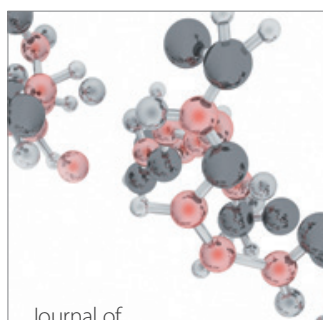

Analytical Methods

in Chemistry

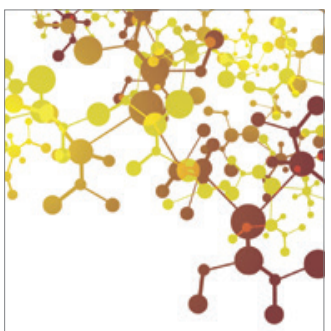

Journal of

Applied Chemistry

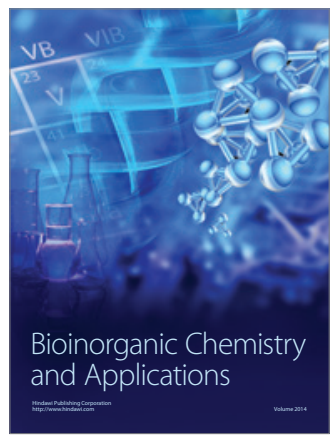

Inorganic Chemistry
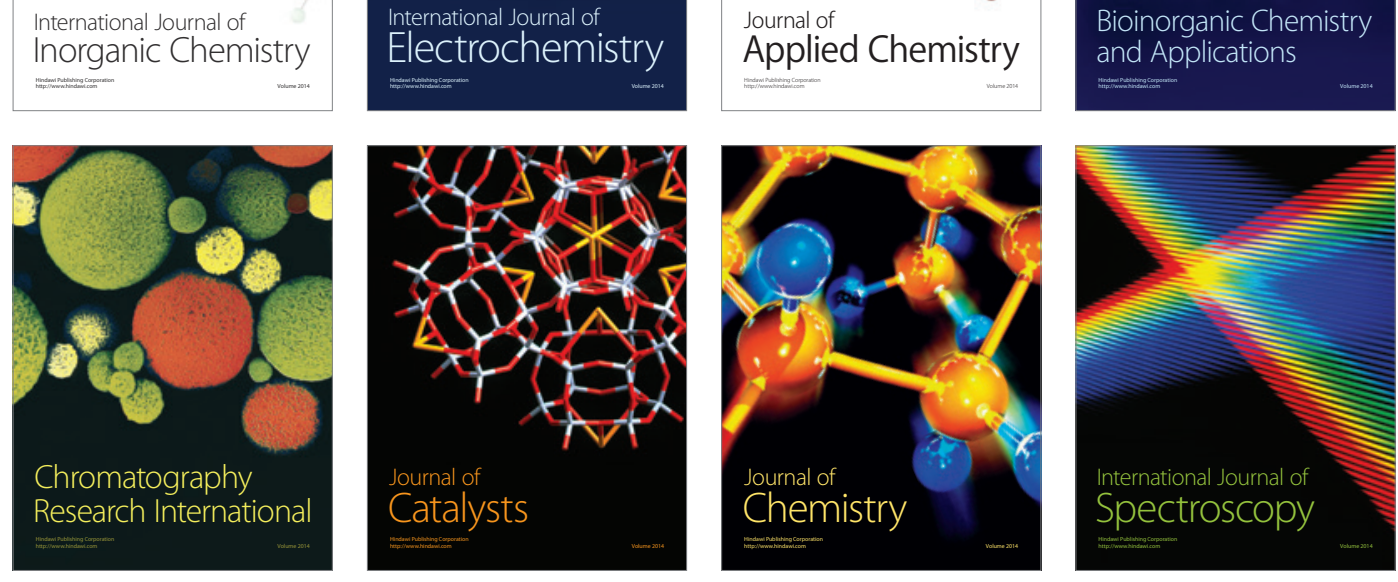